\title{
Análisis de las tesis doctorales sobre fotografía en la universidad española (enero de 2013-marzo de 2016)
}

Analysis of the PhD theses on photography in Spanish universities (January 2013-March 2016)

María Olivera Zaldua (1), Juan Miguel Sánchez Vigil (2), Juan Carlos Marcos Recio (3)

(1) Facultad de Ciencias de la Documentación de UCM, C/Stma Trinidad 37 28010, molivera@ucm.es (2) jmvigil@ucm.es (3) Facultad de Ciencias de la Información de UCM, Av. Complutense s/n 28040, jmarcos@ucm.es

\begin{abstract}
Resumen
Se estudia en este trabajo de investigación la producción y dirección de tesis doctorales sobre fotografía en la universidad española leídas entre enero de 2013 y marzo de 2016. Para el análisis se han aplicado técnicas bibliométricas, empleando como fuente principal la base de datos Teseo del Ministerio de Educación, cuya información se ha contrastado y completado con la hemeroteca Dialnet, el catálogo Cisne, la Red de Bibliotecas Universitarias, el Centro Virtual Cervantes y otras específicas. El resultado ha sido de 96 tesis de las que se describe su temática, distribución por universidades, centros y departamentos. Se plantean las nuevas líneas de investigación en la materia y aquellas otras que están por explorar. Se completa el análisis con un anexo en el que se indican los directores y doctores de las tesis.
\end{abstract}

Palabras clave: Dirección de tesis doctorales. Documentación fotográfica. Fotografía. Tesis doctorales. Producción científica. Universidades. España.

\section{Introducción}

En los tres últimos años (2013-2016) se ha observado un aumento del interés por los estudios de la fotografía en las universidades españolas, planteamiento justificado por la creación de nuevos Grados y Másteres, como el Grado de Fotografía de la Universidad Rey Juan Carlos y la Escuela TAl, o el Máster en Patrimonio Audiovisual de la Facultad de Ciencias de la Información de la Universidad Complutense de Madrid, iniciados en los cursos 2014-2015 y 2012-2013, respectivamente, o por el excelente resultado de otros ya en funcionamiento como el Máster en Fotografía de la Universidad Politécnica de Valencia.

Conviene matizar que tras la implantación del Espacio Europeo de Educación Superior se pusieron en marcha los nuevos estudios de Grado y Máster (Real Decreto del Ministerio de Educación y Ciencia 1393/2007 de 29 de octubre), y la fotografía fue incorporada como asignatura obligatoria en varios másteres, por ejemplo el de Gestión de la Documentación y Bibliotecas de la Facultad

\begin{abstract}
The production and supervision of doctoral theses on photography presented in Spanish universities between January 2013 and March 2016 is studied. Bibliometric techniques were applied, using the Spahichs Ministry of Education's Teseo database as the main source. This information was compared and completed with Dialnet, the Spanish periodical's digital library, the Cisne catalogue, the university Libraries, collective catalogue, the Cervantes Virtual Library and other pertinent sources. 96 theses were located, whose subject matter is described, together with their distribution according to the universities, centres and departments where they were presented. New lines of research were considered along with others which are yet to be explored. The analysis is completed with an addendum that lists the supervisors and doctors of those theses.
\end{abstract}

Keywords: PhD Thesis supervision. Photographic documentation. Photography. PhD Theses. Scientific production. Universities. Spain.

de Ciencias de la Documentación de la Complutense (especialidad en Medios de Comunicación).

Con estos datos se trata de responder a la hipótesis de una mayor atención a la fotografía como disciplina transversal. Precisamente esta cualidad la relaciona con numerosas materias, y ello obliga a realizar un examen en profundidad de la información recopilada al respecto.

Como bibliografía de referencia citaremos los estudios generales sobre tesis doctorales de Delgado, Torres, Jiménez y Ruiz-Pérez (2006), y los del observatorio Actividad Investigadora en la Universidad Española (IUNE), creado para el seguimiento de la Actividad Investigadora de la Universidad Española (Sanz, Filippo, García Zorita y García Preiddy, 2011). Otros temas trabajados son el control y acceso bibliográfico (Moralejo, 2000; Fuentes y Arguimbau, 2010), la comunicación (Jones y Barí, 2000), la publicidad (Marcos Recio, Martínez Pestaña y Blasco López, 2012), la radio y televisión (Repiso, Torres, Delgado, 
2011a, b), la biblioteconomía y documentación (López Yepes, 2008), el cine (Repiso, Torres, Delgado, 2007), las relaciones públicas (Castillo, Xifra, 2006), o la información y documentación (Fuentes Pujol y González Quesada, 2002).

Sobre tesis doctorales de fotografía en la universidad española disponemos de antecedentes y referencias generales (Vega, 2007; Vázquez, 2008), y de la investigación realizada sobre el periodo 1976-2012 (Sánchez Vigil, Olivera, Marcos Recio, 2014). Este último estudio dio como resultado 275 tesis, si bien deben añadirse otras tres dirigidas por el profesor Félix del Valle Gastaminza de la Universidad Complutense que no se recogieron en dicho trabajo. Dos de ellas, las fechadas en 2009 y 2012, no figuraban (ni figuran) en la base de datos Teseo: Sistemas de recuperación de imágenes basados en atributos visuales del contenido, de Sara Pérez Álvarez (2006); La documentación fotográfica en México: Orígenes, evolución y organización de los fondos, de Guadalupe Patricia Ramos Fandiño (2009), y Cobertura fotográfica y representación de la II Guerra Mundial en la prensa gráfica española de Rafael Cros López (2012).

Es por tanto objeto de este artículo conocer la producción y dirección de tesis doctorales sobre fotografía en las universidades españolas entre enero de 2013 y marzo de 2016, enmarcando los resultados en el amplio espectro de la Documentación Fotográfica. Se pretende cuantificar las tesis, valorar su evolución en cuanto a la producción, establecer las temáticas generales y específicas, averiguar la distribución de los trabajos por universidades, centros y departamentos, señalar la aportación de los directores y codirectores de las mismas, e indicar los campos susceptibles de ser explorados.

\section{Metodología}

El estudio, como se ha indicado, comprende el periodo entre enero de 2013 y marzo de 2016, fecha en la que se presentaron las últimas tesis de acuerdo al Real Decreto 99/2011 (1). Se ha realizado a partir de los contenidos de la base de datos Teseo (www.mcu.es/teseo) del Ministerio de Educación, que recoge las tesis depositadas por las universidades, y se ha completado con Dialnet (dialnet.unirioja.es), Catálogo Cisne de la Biblioteca de la Complutense (cine.sim.ucm.es), Red de Bibliotecas Universitarias (rebiun.com), Centro Virtual Cervantes (www.cervantes.com), Consorci de Bibliotecas Universitarias de Cataluña y Centro de Supercomputación de Cataluña (www.tdx.cat/), más la página web Mastesis. En estas dos últimas no se indican los descriptores, por lo que se ha tenido que revisar el resumen y en ocasiones el documento completo.

La base de datos Teseo permite buscar por título y resumen, pero no todas las tesis se encuentran en ella. Por otra parte la información es incompleta en muchos casos, con ausencia de fechas de lectura o los nombres de los departamentos y facultades. También presenta problemas de normalización en cuanto a nombres de personas e instituciones. El uso de términos genéricos, tanto en Teseo como en otras bases de datos para la descripción de contenidos, en lugar de palabras clave específicas en cada caso, dificulta la recuperación de la información. Muchos de los descriptores no se corresponden con los contenidos, lo que ha obligado al repaso de los resúmenes e índices.

Las búsquedas se han realizado a partir de los siguientes términos: foto, fotografía, cámara, prensa, retrato, ilustración, reportero, reportaje y daguerrotipo. El término foto incluye los compuestos del mismo: fotograbado, fotomecánica, fototipia, fotoperiodismo y otros.

Se ha elaborado una base de datos para recoger la información, y a partir de ella se han obtenido los siguientes datos: autor, título, fecha de lectura, universidad, facultad y centro, departamento, director y descriptores. Al mismo tiempo se ha llevado a cabo un trabajo documental para completar los datos pendientes. Para completar la información de las fuentes se ha recurrido cuando ha sido necesario a los departamentos y centros, e incluso a los propios directores y doctores.

Se ha generado una relación de materias vinculadas a la fotografía, de acuerdo a los contenidos, con el fin de dar a conocer las líneas de investigación de mayor interés y aquellas otras menos trabajadas, lo que permite conocer los nichos o espacios abiertos a la investigación. Los resultados que se presentan son los siguientes: producción global; temáticas; aportación de las universidades, centros y departamentos; nombres de directores y codirecciones; y una tabla (anexo) con las tesis por año, nombre del director, universidad y autor.

\section{Resultados}

\subsection{Producción global de tesis}

Las tesis leídas en el periodo analizado fueron 96 , con una media anual de 30 y mensual de 2,5 entre 2013 y 2015, repartidas así: 15 en el año 2013, 24 en 2014 y 33 en 2015 (Figura 1). En el primer trimestre de 2016 se leyeron 24, debido a la extinción de los antiguos programas. De la 
comparativa resulta una clara tendencia al alza, ya que entre 1976 y 2012 se leyeron 278 tesis con una media de menos de 8 por año frente a las 30 actuales.

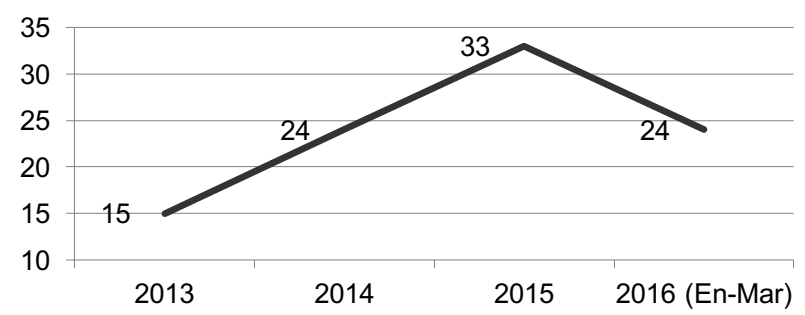

Figura 1. Evolución de la producción de tesis por años

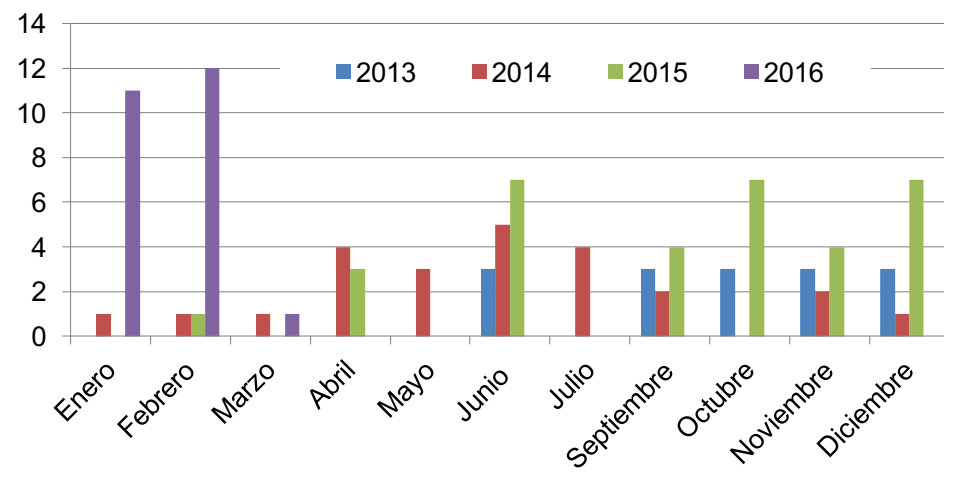

Figura 2. Evolución de la producción de tesis por meses

Durante los cinco primeros meses del año 2013 (enero-mayo) no se leyeron tesis relacionadas con la fotografía en ningún centro; mientras que entre septiembre y diciembre se defendieron 3 por mes. En el año 2014, durante el primer trimestre se presentó una por mes, y entre abril y julio fueron 16 las tesis leídas. De septiembre a diciembre tan solo se defendieron 5 . En el año 2015, se presentaron 11 en el primer semestre ( 7 de ellas en el mes de junio) y 22 de septiembre a diciembre ( 7 de ellas en octubre y otras 7 en diciembre). Debido a la extinción del plan de estudios de doctorado de 2007, se produjo el mayor número de defensas en el primer trimestre de 2016, con un total de 24 tesis de las que 12 fueron presentadas en febrero y 11 en enero (Figura 2).

\subsection{Temáticas}

Para la recuperación de las tesis, como se ha indicado, se han tenido en cuenta los descriptores de las bases de datos, si bien se han realizado las oportunas revisiones en aquellos casos en que los títulos ofrecían dudas al respecto. De las 96 tesis resultan 275 descriptores, destacando el término fotografía en 66 ocasiones. De todos ellos, los directamente relacionados con la foto o la imagen son fotografía artística, tratamiento digital de imágenes, catálogo fotográfico, documentación fotográfica, fotografía deportiva, fotogrametría, imagen, imágenes digitales, producción fotográfica y revista ilustrada. Los más reiterados son historia del arte (13), teoría, análisis y críticas de las bellas artes (13), estética de las bellas artes (9), prensa (7), cinematografía (6), historia del arte de los siglos XIX y XX (5) y pintura (5). Con menos de 5 referencias figuran los 151 términos restantes, entre los que se encuentra una gran cantidad ajena a la disciplina, como por ejemplo: urbanismo, análisis literario, carlismo o teoría de los roles. Es significativo que el término fotografía no aparezca en 30 de las tesis sobre la materia, por lo que hemos de indicar que cuando esta palabra clave no se incluye como descriptor resulta ciertamente complicado relacionar la tesis con la materia.

Una vez analizados los contenidos se han establecido ocho categorías generales para encuadrar las tesis: 1) Arte, 2) Autores (vida y obra), 3) Comunicación, 4) Documentación, 5) Especialización, 6) Historia, 7) Sociología, y 8) Técnica y Tecnología (Tabla I). En el apartado Documentación se incluyen las tesis sobre fondos y colecciones, su tratamiento y análisis; y en el de Sociología los contenidos relacionados con la función social de la imagen fotográfica. Dentro del apartado Especialización se consideran los temas aplicados, tales como Educación o Docencia (7 tesis), Moda (1), Deporte (1) y Turismo (1). Es significativo el escaso número de tesis relacionadas con la historia de la fotografía: orígenes, evolución y desarrollo, movimientos culturales, asociaciones, galerías, aparatos técnicos, etc., así como sobre la vida y obra de los autores (biografías).

\begin{tabular}{lr}
\hline Categoría & $N^{\circ}$ Tesis \\
\hline Arte & 32 \\
\hline Autores (vida y obra) & 5 \\
\hline Comunicación & 15 \\
\hline Documentación & 9 \\
\hline Especialización & 10 \\
\hline Historia & 2 \\
\hline Sociología & 13 \\
\hline Técnica y tecnología & 10 \\
\hline Total & 96 \\
\hline
\end{tabular}

Tabla I. Temática general de los contenidos de las tesis en la universidad española (enero de 2013-marzo de 2016). // Ibersid. 10:2 (2016) 13-20. ISSN 1888-0967. 


\subsection{Producción por universidades}

Las universidades donde se han leído tesis relacionadas con la fotografía entre enero de 2013 y marzo de 2016 son 31 (Tabla II), destacando la Universidad Complutense de Madrid con 24 ( $25 \%$ del total), seguida de la Universidad de Vigo con $7(7,29 \%)$, y de la Autónoma de Madrid, Universitat de Barcelona, Castilla-La Mancha, Granada y Pompeu Fabra, todas ellas con 5 investigaciones $(5,20 \%)$. Con 4 se encuentra la Universidad de Málaga y con 3 la Universidad Autónoma de Barcelona y la Universidad Miguel Hernández de Elche.

\begin{tabular}{|c|c|c|}
\hline$N^{\circ}$ & $\%$ & Universidad \\
\hline 24 & 25 & Universidad Complutense de Madrid \\
\hline 7 & 7,29 & Universidad de Vigo \\
\hline 5 & 5,20 & $\begin{array}{l}\text { Universidad Autónoma de Madrid } \\
\text { Universitat de Barcelona } \\
\text { Universidad de Castilla-La Mancha } \\
\text { Universidad de Granada } \\
\text { Universitat Pompeu Fabra }\end{array}$ \\
\hline 4 & 4,16 & Universidad de Málaga \\
\hline 3 & 3,12 & $\begin{array}{l}\text { Universitat Autónoma de Barcelona } \\
\text { Miguel Hernández de Elche }\end{array}$ \\
\hline 2 & 2,08 & $\begin{array}{l}\text { Universidad de Alicante } \\
\text { Universidad Carlos III de Madrid } \\
\text { Universidad de Extremadura } \\
\text { Universidad La Laguna } \\
\text { Universidad de Murcia } \\
\text { Universidad de Navarra } \\
\text { Universidad Politécnica de Madrid } \\
\text { Universidad de Santiago de Compostela } \\
\text { Universidad de Zaragoza }\end{array}$ \\
\hline 1 & 1,04 & $\begin{array}{l}\text { Universidad de Cantabria } \\
\text { Universidad de Deusto } \\
\text { Universitat de Lleida } \\
\text { Universidad Pablo de Olavide de Sevilla } \\
\text { Universidad del País Vasco } \\
\text { Universitat Politécnica de Valencia } \\
\text { Universidad Ramón Llull } \\
\text { Universidad Rey Juan Carlos } \\
\text { Universidad de Salamanca } \\
\text { Universidad San Pablo-Ceu } \\
\text { Universidad de Sevilla } \\
\text { Universidad de Valladolid }\end{array}$ \\
\hline
\end{tabular}

Tabla II. Producción de tesis por universidades

\subsection{Aportación de las facultades y departamentos}

El número de departamentos donde se han leído tesis sobre fotografía en el periodo estudiado es de 60 , distribuidos en 27 facultades. Se han establecido 5 grupos generales de acuerdo a las enseñanzas impartidas en los centros: Arte (Historia del Arte y Bellas Artes), descrito como AR; Ciencias Sociales (Ciencias de la Información, Ciencias de la Comunicación, Ciencias Jurídicas y Sociales, Psicología y Documentación), indi- cado como CS; Humanidades (Educación, Filología, Filosofía y Letras, Geografía e Historia), denominadas HU, y Ciencias (Ciencias del Deporte, Económicas y Empresariales, Arquitectura, Informática, Ingeniería, Matemáticas y Agroforestal), marcados como $\mathrm{Cl}$. De las 96 tesis, en las Facultades relacionadas con el Arte se han leído 29 $(30,20 \%)$, en las de Ciencias Sociales y Jurídicas 23 (23,95\%), en Humanidades 30 (31,25\%) y en Ciencias 14 (14,58 \%).

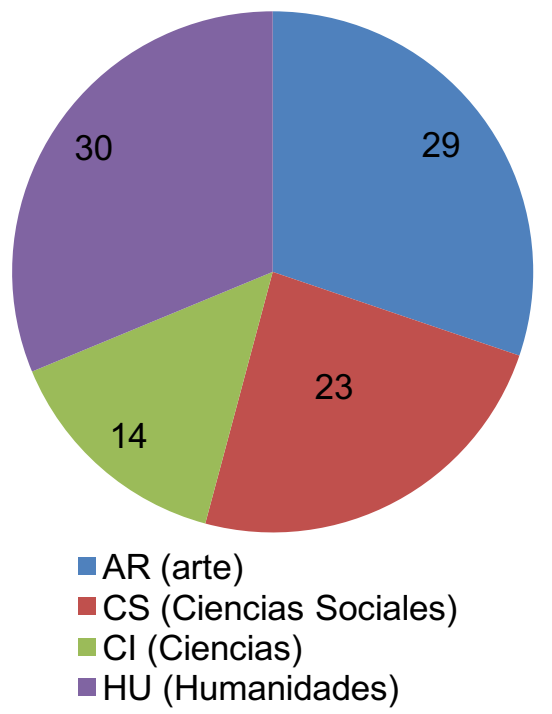

Figura 3. Tesis por especialidades en Facultades

De las 29 tesis sobre Arte, 8 corresponden a la Universidad Complutense de Madrid, 5 a Vigo, 4 a Castilla-La Mancha y a la Universidad de Barcelona, 3 a la Universidad Miguel Hernández de Elche, y el resto todas con una. En cuanto a las tesis de Humanidades, las universidades de mayor producción con 4 trabajos son: Autónoma de Madrid (Facultad de Filosofía y Letras) y Complutense (2 tesis en la Facultad de Educación y una en Filología y Filosofía), seguidas de un amplio grupo con 2 tesis. Las relacionadas con Ciencias Sociales se distribuyen de la siguiente manera: 7 tesis en la Facultad de Ciencias de la Información de la UCM, 4 en la de Ciencias de la Documentación de la UCM, 3 en la de Ciencias de la Comunicación de la Universidad de Málaga y en la Pompeu Fabra de Barcelona. El resto está por debajo de 2 investigaciones. En la producción sobre Ciencias el reparto es equivalente, con 2 tesis presentadas en la Universidad Politécnica de Madrid (Escuela Técnica Superior de Arquitectura) y en el resto distribuido en una por cada Facultad.

Como ya hemos indicado, son 60 los departamentos en los que se han leído tesis sobre Fotografía, lo que abunda en la transversalidad de la 
materia. Destaca el Departamento de Arte de la Facultad de Bellas Artes de la Universidad de Castilla-La Mancha con 4, seguido del Departamento y Facultad del mismo nombre en la Universidad Miguel Hernández de Elche con 3. Tam- bién son importantes por su producción los departamentos de Dibujo II y Didáctica de la expresión plástica de la Facultad de Bellas Artes de la Universidad Complutense de Madrid, ambos con 3 tesis. El resto de departamentos cuentan con uno o dos trabajos (Tabla III).

\begin{tabular}{|c|c|c|c|}
\hline Departamento & Facultad & Universidad & Tesis \\
\hline Arquitectura & Escuela T.S. Arquitectura & Sevilla & 1 \\
\hline Arte & Bellas Artes & Miguel Hernández (3), Castilla-La Mancha (4) & 7 \\
\hline Bellas Artes & Bellas Artes & Murcia, Vigo & 2 \\
\hline Biblioteconomía y Documentación & Bellas Artes & UCM & 4 \\
\hline CC. de la Comunicación & CC. Documentación & Santiago & 1 \\
\hline $\begin{array}{l}\text { CC. de la Documentación e Historia de la } \\
\text { Ciencia }\end{array}$ & CC. Comunicación & Zaragoza & 1 \\
\hline Comunicació & Comunicación & Pompeu Fabra & 3 \\
\hline Comunicación Audiovisual y Publicidad & CC. Comunicación & Málaga & 2 \\
\hline Comunicación Audiovisual y Publicidad II & CC. Información & UCM & 2 \\
\hline Comunicación Social & CC. Información & UCM & 1 \\
\hline Dibujo & Bellas Artes & Vigo (2), UCM (2) & 4 \\
\hline Dibujo I & Bellas Artes & UCM & 1 \\
\hline Dibujo II & Bellas Artes & UCM & 3 \\
\hline $\begin{array}{l}\text { Didáctica de la Expresión corporal, } \\
\text { plástica y musical }\end{array}$ & Educación & Granada & 2 \\
\hline $\begin{array}{l}\text { Didáctica de la Expresión musical, } \\
\text { plástica y corporal }\end{array}$ & CC. del Deporte & Extremadura & 2 \\
\hline Didáctica de la Expresión plástica & Bellas Artes & UCM & 3 \\
\hline Didáctica Especiales & Educación & Vigo & 1 \\
\hline Didáctica y Org. Escolar & Educación & UCM & 1 \\
\hline $\begin{array}{l}\text { Didáctica, Org. Escolar y métodos de } \\
\text { investigación }\end{array}$ & Educación & Vigo & 1 \\
\hline Dusseny i imatge & Bellas Artes & Barcelona & 1 \\
\hline Escultura & Bellas Artes & Barcelona, Vigo, Politènica Valencia & 2 \\
\hline $\begin{array}{l}\text { Expresión gráfica en arquitectura e } \\
\text { ingeniería }\end{array}$ & Escuela T.S. Arquitectura & Granada & 1 \\
\hline Filología & Ciencias Jurídicas & Rey Juan Carlos & 1 \\
\hline Filología catalana i comunicació & Letras & Lleida & 1 \\
\hline Filología Española II & CC. Información & UCM & 1 \\
\hline $\begin{array}{l}\text { Filología Española, lingüística general y } \\
\text { teoría literaria }\end{array}$ & Filosofía y Letras & Autónoma Madrid & 1 \\
\hline $\begin{array}{l}\text { Filología Románica, filología eslava y } \\
\text { lingüística general }\end{array}$ & Filología & UCM & 1 \\
\hline Filosofía IV & Filosofía & UCM & 1 \\
\hline Financiación e Investigación comercial & $\begin{array}{l}\text { CC. Económicas y } \\
\text { empresariales }\end{array}$ & Autónoma Madrid & 1 \\
\hline Geografía, Historia y Filosofía & Humanidades & Pablo Olavide & 1 \\
\hline Historia contemporánea & Filosofía y Letras & Autónoma Madrid & 1 \\
\hline $\begin{array}{l}\text { Historia de la filosofía, estética i filosofía } \\
\text { de la cultura }\end{array}$ & Filosofía & Barcelona & 1 \\
\hline Historia del Arte & Bellas Artes, Filosofía y Letras & $\begin{array}{l}\text { Barcelona, Castilla-La Mancha, Navarra, } \\
\text { Málaga, Zaragoza, Autónoma Madrid }\end{array}$ & 6 \\
\hline Historia del Arte y filosofía & Geografía e Historia & Autónoma Madrid & 1 \\
\hline Historia Moderna y Contemporánea & Filosofía y Letras & Cantabria & 1 \\
\hline Historia, $\mathrm{H}^{\mathrm{a}}$ Arte y Geografía & Filosofía y Letras & Navarra & 1 \\
\hline Humanidades & Humanidades & Pompeu Fabra & 2 \\
\hline Humanidades Contemporáneas & Filosofía y Letras & Alicante & 1 \\
\hline Información y Documentación & Comunicación y Doc. & Murcia & 1 \\
\hline Ingeniería Agroforestal & Ingeniería Agroforestal & Santiago & 1 \\
\hline Ingeniería de Software e Inteligencia & Informática & UCM & 1 \\
\hline
\end{tabular}
en la universidad española (enero de 2013-marzo de 2016). // Ibersid. 10:2 (2016) 13-20. ISSN 1888-0967. 


\begin{tabular}{|c|c|c|c|}
\hline artificial & & & \\
\hline $\begin{array}{l}\text { Ingeniería Informática y } \\
\text { Telecomunicación }\end{array}$ & Ingeniería & Deusto & 1 \\
\hline Instituto Estudios Mujer & Instituto Estudios Mujer & Granada & 1 \\
\hline Matemáticas & Matemática & País Vasco & 1 \\
\hline Periodismo & $\begin{array}{l}\text { CC. Com. y Humanidades, CC. } \\
\text { Comunicación }\end{array}$ & Málaga, San Pablo CEU & 2 \\
\hline Periodismo I & CC. Información & UCM & 1 \\
\hline Periodismo IV & CC. Información & UCM & 1 \\
\hline Periodismo y Comunicación & CC. Comunicación & Autónoma Barcelona & 1 \\
\hline Periodismo Com. Audiovisual & Humanidades, CC. y Doc. & Carlos III & 2 \\
\hline Pintura & Bellas Artes & UCM, Vigo, Granada & 3 \\
\hline Pintura y escultura & Geografía e Historia & La Laguna & 1 \\
\hline Proyectos arquitectónicos & Escuela T.S. Arquitectura & Politécnica Madrid & 2 \\
\hline Psicología & Psicología & Ramon Llul & 1 \\
\hline $\begin{array}{l}\text { Publicitat, RI. Publiques i Com. } \\
\text { Audiovisual }\end{array}$ & CC. Comunicación & Autónoma Barcelona & 1 \\
\hline Sociología II & CC. Econ. y Empresariales & Alicante & 2 \\
\hline Sociología y Comunicación & Ciencias Sociales & Salamanca & 1 \\
\hline $\begin{array}{l}\text { Teoría del Conocimiento, Estética e } \\
\text { Historia del Pensamiento }\end{array}$ & CC. Información & UCM & 1 \\
\hline Teoría e Historia del Arte & Filosofía y Letras & Autónoma Madrid & 1 \\
\hline Traducción e Interpretación & Artes y Humanidades & Autónoma Madrid & 1 \\
\hline $\begin{array}{l}\text { Urbanismo y Representación de la } \\
\text { Arquitectura }\end{array}$ & Escuela T.S. Arquitectura & Valladolid & 1 \\
\hline
\end{tabular}

Tabla III. Tesis por especialidad en Departamentos

\begin{tabular}{|c|c|c|c|c|}
\hline Directores (120) & Tesis (96) & Universidad & Facultad & $\%$ \\
\hline Sánchez Vigil, J.M. & 4 & Complutense & CC. Documentación & 4,16 \\
\hline Calzado Almodóvar, Z. & 2 & Extremadura & CC. Deporte & 2,08 \\
\hline Elías Pérez, C.J. & 2 & $\begin{array}{c}\text { San Pablo-CEU } \\
\text { Carlos III }\end{array}$ & $\begin{array}{l}\text { Humanidades y Com. } \\
\text { Humanidades, Com. y Doc. }\end{array}$ & 2,08 \\
\hline Leyra Soriano, A.M. & 2 & Complutense & $\begin{array}{l}\text { CC. Información } \\
\text { Filosofía }\end{array}$ & 2,08 \\
\hline Roldán Ramírez, J. & 2 & Granada & Educación & 2,08 \\
\hline García García, F. & 2 & Complutense & CC. Información & 2,08 \\
\hline Legido García, V. & 2 & Complutense & Bellas Artes & 2,08 \\
\hline 102 Directores & 1 & & & 1,04 \\
\hline
\end{tabular}

Tabla IV. Directores de tesis

\begin{tabular}{lrl}
\hline \multicolumn{1}{c}{ Año } & N $^{\circ}$ & Codirectores \\
\hline 2013 & 3 & $\begin{array}{l}\text { Vilchis Esquivel, L. C. y Domenech Ibáñez, I.; López Suárez, M. y Legido García, M. V.; Popeanga Chelaru, E. } \\
\text { y Millán Alba, J. A }\end{array}$ \\
\hline 2014 & 6 & $\begin{array}{l}\text { Acaso López Bosch, M. y Aznar Almazán, S.; Rayón Rumayor, L. y Bautista García Vera, A., Palacios Garrido, A. } \\
\text { y Fernández Ruiz, B.; Abad Tejerina, M. J. y García García, F.; Gil Docampo, M. L. y Ortiz Sanz, J.; Buzán Bran, X. } \\
\text { M. y Rodríguez Caldas, M. M. }\end{array}$ \\
\hline 2015 & 8 & $\begin{array}{l}\text { Prado Fonts, C. y Beltrán Antolín, J.; Ruiz San Miguel, F. J. y Gómez Gómez, A. J.; Pastor Bravo, J. Ll. y Herranz } \\
\text { Pascual, Y.; Albalate Gauchía, I. y Martín Martínez, J. V.; Ariza Pomareta, J. y Meseguer Mayoral, R.; Picón Ruiz, } \\
\text { Artzai y Pardo Zubiaur, D.; Cid Sabucedo, A. y Parilla Latas, M. A.; Taboas Pais, M. I. y Rey Cao, A. I. }\end{array}$ \\
\hline 2016 & 7 & $\begin{array}{l}\text { Sazatornil Ruiz, L. S. y García Felguera, M. S.; Tapias Gil, M. D. y Ameller Ferretjans, C.; Guerra Rojas, J. C. y Balló } \\
\text { Fantova, J.; Aguilera Pedrosa, A. y Cruz Rodríguez, M.; Casado de Amezua Vázquez, J. y García Gil, T. F.; Aguado } \\
\text { Terrón, J. M. y Mira pastor, E.; Herrera García, F. J. y Ollero Lobato, F }\end{array}$ \\
\hline Total & 24 &
\end{tabular}

Tabla VI. Codirectores de tesis doctorales en la universidad española (enero de 2013-marzo de 2016). // Ibersid. 10:2 (2016) 13-20. ISSN 1888-0967. 


\subsection{Directores de tesis}

Los directores de tesis son 120 , ya que 24 han sido codirigidas. En la Tabla IV se observa claramente el reparto equitativo en cuanto a esta actividad científica. Solo 8 profesores han dirigido dos o más tesis, cuatro de ellos pertenecientes a la Universidad Complutense de Madrid y el resto a las de Extremadura, Navarra, San Pablo-CEU, Carlos III y Granada. Como conclusión a este respecto hemos de indicar una vez más que consideramos la fotografía como materia y disciplina transversal, lo que justifica el elevado número de directores, en su mayoría catedráticos y titulares de universidad.

\subsection{Codirectores}

La codirección de tesis doctorales ha aumentado considerablemente en los últimos años, debido por una parte a cuestiones metodológicas y de contenidos, y por otra al veto que la normativa impone a los Profesores Ayudantes Doctores, a los que se permite la codirección y no la dirección, en una evidente contradicción, ya que la valoración por la dirección de tesis es igual para los codirectores.

En el caso que nos ocupa las 24 tesis codirigidas han contado con dos profesores, destacando en lo que se refiere a centros la Universidad Complutense de Madrid (6) y la de Vigo (4). En la Universidad de Barcelona fueron 2 las tesis codirigidas y en el resto solo una (Tabla $\mathrm{V}$ ).

\begin{tabular}{lc}
\hline Universidad & Tesis \\
\hline Universidad Complutense de Madrid & 6 \\
\hline Universidad de Vigo & 4 \\
\hline Universitat de Barcelona & 2 \\
\hline Universitat Politènica de Valencia & 1 \\
\hline Universidad de Murcia & 1 \\
\hline Miguel Hernández de Elche & 1 \\
\hline Universidad de Granada & 1 \\
\hline Universidad de Santiago de Compostela & 1 \\
\hline Universitad Pompeu Fabra & 1 \\
\hline Universidad Pablo de Olavide de Sevilla & 1 \\
\hline Universidad del País Vasco & 1 \\
\hline Universidad de Cantabria & 1 \\
\hline Universidad de Málaga & 1 \\
\hline Universitat Autónoma de Barcelona & 1 \\
\hline Universidad de Castila-La Mancha & 1 \\
\hline Total & 24 \\
\hline
\end{tabular}

Tabla V. Tesis codirigidas en las universidades
En el año 2013 se codirigieron 3 tesis, en 2014 fueron 6 y en 2015 sumaron 8 . El aumento es por tanto progresivo, implicando en el primer caso a seis profesores, en el segundo a 12 y en el tercero a 16. En los tres primeros meses de 2016 fueron 7 las tesis codirigidas, con 14 profesores implicados. Como resumen diremos que el balance es muy positivo tanto por el número de tesis como por los codirectores. En la Tabla VI se indican los nombres de los profesores.

\section{Conclusiones}

La investigación sobre fotografía en la universidad española continua siendo una asignatura pendiente, y ello a pesar del incremento de trabajos detectados en los últimos años. Tanto la producción, como la diversidad de materias, el número de facultades y departamentos implicados, así como la cantidad de profesores, confirman que la fotografía es una disciplina transversal cuyos usos y aplicaciones son muy diversos.

Se concluye de la investigación que se ha producido un aumento progresivo de las tesis doctorales sobre Fotografía, muy considerable si tenemos en cuenta que en el periodo 1976-2012 se leyeron 278 investigaciones, y que solo entre enero de 2013 y marzo de 2016 fueron 96 las tesis defendidas, es decir que en tres años se ha leído el equivalente al $30 \%$ de las presentadas en los 37 años anteriores.

Las tesis se encuentran muy repartidas en las universidades, facultades y departamentos, y los centros que destacan lo hacen en proporción al número de alumnos. El mayor número se relaciona con el Arte (32) y con la Comunicación y Documentación (24), mientras que sobre Tecnología la cifra es baja sobre el total, con 10 trabajos de $96(10,41 \%)$. Es significativo también el escaso número de tesis relacionadas con la historia de la fotografía: desarrollo cronológico, movimientos culturales, etc., así como sobre la vida y obra de los autores (biografías).

En consecuencia se advierte que tanto cuantitativa como cualitativamente las posibilidades de investigación son amplias. Son muchas las temáticas y contenidos por explorar, sobre todo en lo que se refiere a la autoría y a la aplicación de la fotografía a las ciencias y al arte.

La transversalidad de la disciplina y la presencia de la imagen fotográfica en la mayor parte de las actividades sociales justifican la necesidad de impulsar la investigación en una disciplina que soporta estudios en todas las áreas de conocimiento: ciencias, ciencias sociales y jurídicas, arte y humanidades. Con el fin de conseguir los en la universidad española (enero de 2013-marzo de 2016). // Ibersid. 10:2 (2016) 13-20. ISSN 1888-0967. 
objetivos que se plantean se advierte la necesidad de revisar los planes de estudio para incorporar asignaturas o bien temas en los programas específicos relacionados con las imágenes, y de manera concreta con las fotografías, ya que soportan, enriquecen y matizan la docencia, contribuyendo a su innovación.

Por último, es altamente recomendable realizar estudios periódicos como el que aquí se plantea sobre las investigaciones en fotografía, al objeto de establecer un observatorio que permitan el seguimiento a la vez que despierten el interés en la materia.

\section{Notas}

(1) El Real Decreto 99/2011 del 28 de enero de 2011 limitaba a 5 años el plazo de presentación y defensa de las tesis a los estudiantes que a la entrada en vigor del mismo ya hubieran iniciado estudios de doctorado reguladas por normativas anteriores. Por tanto, desde el 11 de febrero de 2016 quedaron extinguidos todos los programas regulados por normativa anterior al citado Real Decreto, excepto para los estudiantes que hubieran iniciado los estudios de Doctorado por el Real Decreto 1393/2007 de 29 de octubre en los cursos 2011-12, 2012-13 o 2013-14 que en aplicación de la disposición transitoria segunda de mencionado Real Decreto 99/2011, dispondrán hasta el 30 de septiembre de 2017 para la defensa de la tesis.

\section{Referencias}

Castillo, A.; Xifra J. (2006). Investigación bibliométrica en las tesis doctorales españolas sobre relaciones públicas (1965-2005). // Análisis. 34, 141-161.

Delgado, E. Torres, D.; Jiménez E.; Ruiz-Pérez, R. (2006). Análisis bibliométrico y de redes sociales aplicado a las tesis bibliométricas defendidas en España (1976-2002). // Revista Española de Documentación Científica. 29:4, 493-524.

Fuentes i Pujol, M. E.; González Quesada, A. (2002). Tesis doctorales en España en información y documentación 1976-2001. // Morán Suárez, M. ${ }^{a}$ A.; Rodríguez López, M. C. (coord.) La documentación para la investigación: homenaje a José Antonio Martín Fuertes. León: Universidad de León.

Jones, D. E.; Bari I Queralt, B. (2000).Investigación sobre Comunicación en España; aproximación bibliométrica a las tesis doctorales (1926-1998). Barcelona: ComCat, 2000.

López Yepes, J.; Fernández Bajón, M.T.; Orera Orera, Luisa; Sánchez Vigil, J.M. (2008). Criterios para la evaluación de tesis doctorales // Revista General de Información y Documentación. 18:1, 293-322.

Marcos Recio, J. C.; Martínez Pestaña, M. J.; Blasco López M. F. (2012). Producción y dirección de tesis doctorales sobre publicidad en la universidad española (1971-2010) // Revista Española de Documentación Científica. 35:3, 433-452.

Ministerio de Educación y Ciencia (2007). Real Decreto del Ministerio de Educación y Ciencias 1393/2007, de 29 de octubre por que se establece la ordenación de las enseñanzas universitarias oficiales. // BOE. 260 (30/10/2007) 4437-44048.

Moralejo Álvares, M. R. (2000). La tesis doctorales en las universidades españolas, control bibliográfico y acceso // Revista General de Información y Documentación. 10 (1) 235-243.
Repiso, R.; Delgado E.; Torres D. (2007). Análisis bibliométrico de la producción española de tesis doctorales sobre cine. // Bort Gual, I.; García Catalán, S.; Martín Núñez, M. (eds.). Actas del IV Congreso Internacional sobre análisis fílmicos, nuevas tendencias e hibridaciones de los discursos audiovisuales en la cultura digital contemporánea. Castellón: Universidad Jaume I, 2007.

Repiso, R.; Torres, D. (2011a). Análisis bibliométrico y de redes sociales en tesis doctorales españolas sobre televisión (1976-2007). // Comunicar. 37:19, 151-159.

Repiso, R.; Torres, D. (2011b). Análisis de la investigación sobre radio en España: una aproximación a través del análisis bibliométrico y de redes sociales de las tesis doctorales defendidas en España entre 1976-2008. // Estudios sobre el mensaje periodístico 17:2, 417-429.

Sánchez Vigil, J.M. (2006). El documento fotográfico: Historia, usos, aplicaciones. Gijón: Trea.

Sánchez Vigil, J.M.; Marcos Recio, J.C.; Olivera Zaldua, M. (2014). Tesis doctorales sobre fotografía en la universidad española: análisis de la producción científica (19762012). // Revista Española de Documentación Científica. 37:1, 1-14.

Sanz Casado, E.; Filippo, D.; García Zorita, J.C.; García Preiddy, E. (2011). Observatorio IUNE: una nueva herramienta para el seguimiento de la actividad investigadora del sistema universitario español. // Bordon Revista de pedagogía. 63:2, 101-116.

Vázquez Casilla, F. (2008). La historia y la fotografía en España (1975-1999). Estado de la cuestión. // Actas del tercer Congreso de Historia de la Fotografía. Zarautz: Photomuseum, 215-227.

Vega, C. (2007). La fotografía en la Universidad: una historia con futuro. // Actas del II Congreso de Historia de la Fotografía. Zarautz: Photomuseum, 66-71.

Enviado: 2016-03-31. Aceptado: 2016-06-03. en la universidad española (enero de 2013-marzo de 2016). // Ibersid. 10:2 (2016) 13-20. ISSN 1888-0967. 